\title{
Allergy to laboratory animals: an epidemiological study
}

Kohji Aoyama, Atsushi Ueda, Fumi Manda, Toshio Matsushita, Tomoyuki Ueda, Chuhei Yamauchi

\begin{abstract}
A large cross sectional survey was carried out using a self administered questionnaire to examine the prevalence of laboratory animal allergy (LAA) and the factors associated with its development. Out of 5641 workers who were exposed to animals at 137 laboratory animal facilities in Japan, $23.1 \%$ had one or more allergic symptoms related to laboratory animals. The commonest symptom was rhinitis. About $70 \%$ of LAA subjects developed symptoms during their first three years of exposure. Atopy (past and family history), the number of animal species handled, and the time spent in handling correlated significantly with the development of LAA as did some types of job. A close relation between nasal symptoms and exposure to rabbits and between skin symptoms and exposure to rats were found. LAA subjects developed symptoms most quickly to rabbits.
\end{abstract}

Laboratory animal allergy (LAA) is receiving increased attention and it is now believed that many persons suffer from allergic symptoms related to laboratory animals. Laboratory animal allergy has been recognised as a health problem for those who work with laboratory animals in Japan but there are few epidemiological surveys of LAA with large numbers of subjects.

Many studies on LAA have been carried out in the United Kingdom and the United States. ${ }^{1-8}$ The prevalence of LAA has been rated at between 11 and $30 \%$. ${ }^{9}$ From the viewpoint of prevention, three basic factors associated with the development of LAA have been considered. ${ }^{4-11}$ These are the predisposition

Department of Environmental Medicine, Faculty of Medicine, Kagoshima University

K Aoyama, A Ueda, F Manda, T Matsushita

Institute of Laboratory Animal Sciences, Faculty of Medicine, Kagoshima University, Sakuragoaka, Kagoshima 890, Japan

T Ueda, C Yamauchi of the subject, the allergenicity of the substances derived from animals, and the nature and intensity of exposure.

We carried out a large scale survey among 5641 animal handlers in 137 laboratory animal facilities to clarify the size of the problem of LAA in Japan, and to consider the various factors involved in the development of LAA.

\section{Subjects and methods}

A self administered questionnaire was designed by us and contained questions on sex, age, history and family history of allergic diseases, smoking and pet owning history, duration of working with laboratory animals, job titles, job contents, frequency of contact with animals, species, time spent handling animals, and use of protective equipment. Questions dealing with symptoms asked about experience of nasal, eye, respiratory, and skin symptoms and the association between symptoms and laboratory animals. Further, the subjects with symptoms were specifically asked about the time to first symptoms, the relation between the symptoms and animals, species and time of exposure to animals related to symptoms, and about the effectiveness of protective equipment etc. When subjects reported some symptoms, they were systematically questioned about further symptoms.

The questionnaire was sent to 164 laboratory animal facilities in Japan and handed to 8765 handlers including researchers, assistants, and husbandry personnel. Replies were received from 137 facilities $(84 \%)$. Of these, 76 were medical schools, 57 were research institutes, and four were breeders. Out of 8765 subjects, 5641 replied $(64 \cdot 4 \%)$. All of them had been exposed to laboratory animals and so they were named the exposed group. This group was divided into two sub groups, LAA and non-LAA. In studying the correlation between the development of LAA and predisposing factors, 252 employees without occupational exposure to laboratory animals were selected from our medical school as a control group. The exposed and control groups were young (mean age $33 \cdot 2$ (SD 11.6) and $33 \cdot 4$ (SD 10.5) years respectively) and contained more men than women (man: woman $2 \cdot 7$ and 1.03 respectively).

In this study, animal handlers were defined as the 
Table 1 Prevalence of $L A A$ in 137 institutes

\begin{tabular}{lcr}
\hline Type of facility & $\begin{array}{l}\text { No of } \\
\text { subjects }\end{array}$ & $\begin{array}{l}\text { No of } L A A \\
\text { subjects }(\%)\end{array}$ \\
\hline Medical schools & 2806 & $616(22 \cdot 0)$ \\
Research institutes & 2697 & $660(24 \cdot 5)$ \\
Breeders & 138 & $28(20 \cdot 3)$ \\
Total & 5641 & $1304(23 \cdot 1)$ \\
\hline
\end{tabular}

users or staff of a facility who were exposed to laboratory animals, or the substances derived from them, or both. The LAA subjects were defined as workers who had allergic symptoms related to laboratory animals-namely, sneezing, rhinitis, conjunctivitis, wheezing or cough, asthma, and urticaria. The following markers of atopy were assessed in all subjects: (1) past history of allergic rhinitis, conjunctivitis, asthma, and urticaria to pollen, house dust, food and unknown allergens; (2) family history of the same symptoms.

The results were computed and analysed with the SPSS computer program package. The $\chi^{2}$ test was used to detect significance of association. The level of significance accepted was $\mathrm{p}<0.05$.

\section{Results}

THE OCCURRENCE OF LAA IN JAPAN

Out of 5641 subjects, $1304(23 \cdot 1 \%)$ had one or more allergic symptoms related to laboratory animals (table 1). No significant difference in the prevalence of LAA was found between the three types of facilities.

Figure 1 shows that LAA subjects had various combinations of nasal, respiratory, and skin symptoms (nasal symptoms are combined with eye symptoms in this figure); $43.6 \%$ of LAA subjects had two or more symptoms. The proportion of LAA subjects suffering from nasal or eye symptoms alone $(39.7 \%)$ was largest followed by the combination of nasal or eye and skin symptoms $(19 \cdot 3 \%)$, nasal or eye, skin,

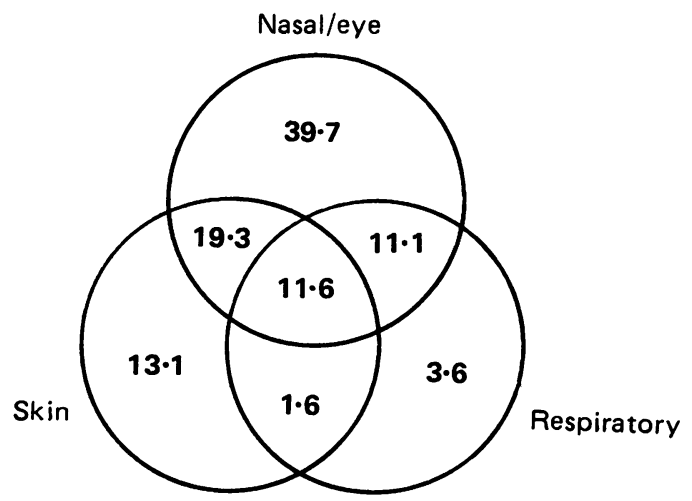

Figure 1 Combinations of symptoms in LAA subjects (\%).

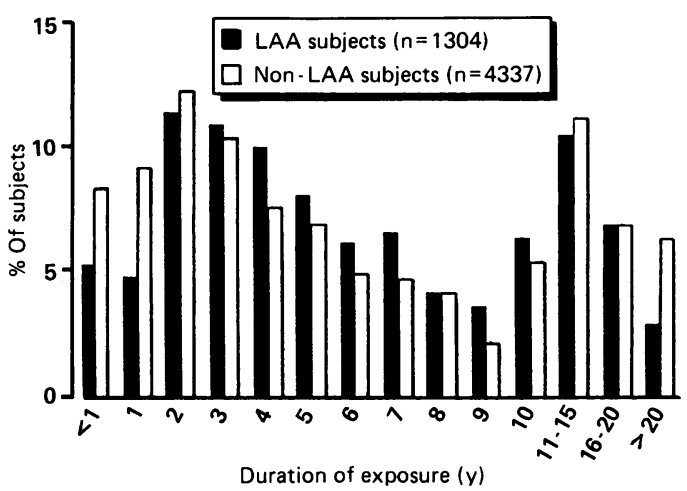

Figure 2 Distribution of duration of exposure to laboratory animals.

and respiratory symptoms $(11.6 \%)$ and nasal or eye and respiratory symptoms $(11 \cdot 1 \%)$. Of all LAA subjects, $81.7 \%$ had nasal or eye symptoms and most of them complained of rhinitis; $45.6 \%$ had skin symptoms and $16.0 \%$ of them complained of contact urticaria; $27.9 \%$ had respiratory symptoms and $33.2 \%$ of them complained of asthma. No subjects had asthma without other symptoms.

Figure 2 shows the distribution of the duration of exposure to laboratory animals in LAA and nonLAA subjects at the time of the survey. The LAA subjects had a significantly shorter time in exposure than non-LAA subjects $(\mathrm{p}<0.01)$.

Figure 3 shows the distribution of latency and the period from first exposure to first manifestation of LAA symptoms in LAA subjects. About $70 \%$ of LAA subjects reported the occurrence of first symptoms during their first three years of exposure, $33 \%$ of them in the first year. The proportion of the subjects who reported the occurrence of the symptoms during the first year of exposure was highest among those with respiratory symptoms.

About $61 \%$ of the subjects in this survey handled two or more species of animal. Table 2 shows the number of persons handling different species and the prevalence of LAA by different species. Rats and mice were used most frequently $(62.4 \%$ and $57.5 \%$ respectively). The subjects handling guinea pigs had the highest prevalence of LAA $(31.0 \%)$, then cats $(30 \cdot 1 \%)$, rabbits $(29 \cdot 7 \%)$, and mice $(26 \cdot 1 \%)$.

We surveyed the effectiveness of protective equipment, such as masks, gloves, and glasses in the prevention of LAA (table 3 ). Some $46 \%$ of those with nasal symptoms reported that the use of protective equipment helped to reduce symptoms. Skin $(44.6 \%)$, respiratory $(44.8 \%)$, and eye symptoms $(31.0 \%)$ were less well prevented and 36.5 to $56.4 \%$ of subjects with LAA symptoms also reported protective equipment to be "not available" or "not regularly available". 


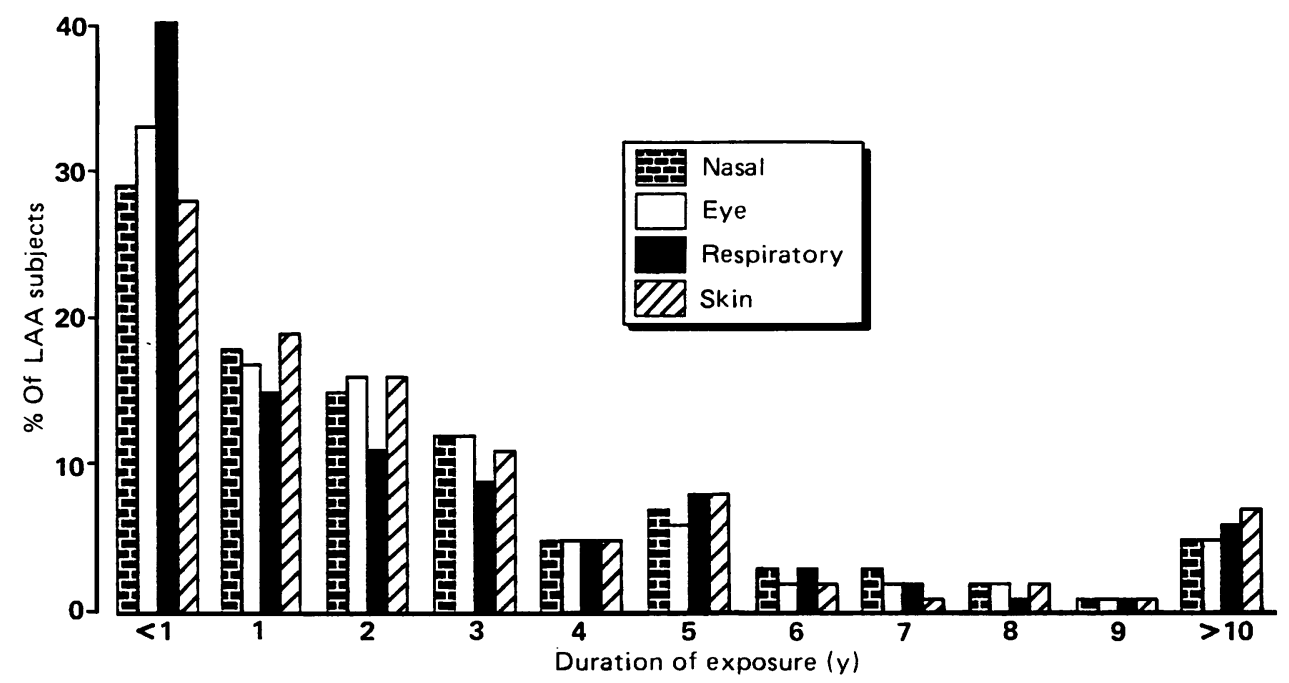

Figure 3 Distribution of latency by different symptoms.

\section{FACTORS RELATED TO THE DEVELOPMENT OF LAA}

Atopy, exposure density, and animal species were examined as the factors related to the development of LAA.

Of all LAA subjects, $59 \cdot 2 \%$ had a history of allergy whereas $30.4 \%$ of the non-LAA subjects and $30.7 \%$ of the control subjects had such a history (table 4 ). The differences were significant. A similar tendency was also found for family history, although the frequencies were lower than those of history in all groups.

As the indices of exposure density, we chose job category, the frequency of handling animals, and the number of animal species handled. Job category was defined by selecting from four categories (table 5). Several subjects selected two or more job categories. The prevalence of LAA was similar in researchers, experimental assistants, and animal husbandry personnel. Staff in charge of cleaning and washing

Table 2 The prevalence of $L A A$ symptoms in handlers by different animal species

\begin{tabular}{lcl}
\hline Species & No of handlers $(\%)$ & Prevalence of LAA \\
\hline Mouse ${ }^{\star}$ & $3246(57 \cdot 5)$ & $26 \cdot 1$ \\
Rat $^{\star}$ & $3518(62 \cdot 4)$ & $24 \cdot 9$ \\
Guinea pig ${ }^{\star}$ & $1482(26 \cdot 3)$ & $31 \cdot 0$ \\
Rabbit ${ }^{\star}$ & $2198(39 \cdot 0)$ & $29 \cdot 7$ \\
Hamster & $589(10 \cdot 4)$ & $25 \cdot 5$ \\
Dog ${ }_{\text {Cat }}^{\star \star}$ & $1580(28 \cdot 0)$ & $24 \cdot 9$ \\
Monkey & $579(10 \cdot 3)$ & $30 \cdot 1$ \\
Others & $692(12 \cdot 3)$ & $23 \cdot 6$ \\
\hline
\end{tabular}

*Significant between handlers and non-handlers of the species $(\mathrm{p}<0.05)$. $\star \star$ Significant between handlers and non-handlers of the species
$(p<0 \cdot 01)$.
Table 3 Effectiveness of protective equipment for preventing LAA symptoms

\begin{tabular}{lclcc}
\hline & $\begin{array}{l}\text { Nasal } \\
(n=1022)\end{array}$ & $\begin{array}{l}\text { Eye } \\
(n=564)\end{array}$ & $\begin{array}{l}\text { Respiratory } \\
(n=364)\end{array}$ & $\begin{array}{l}\text { Skin } \\
(n=595)\end{array}$ \\
\hline Available (\%) & $46 \cdot 7$ & $31 \cdot 0$ & $44 \cdot 8$ & $44 \cdot 2$ \\
Not available (\%) & $10 \cdot 3$ & $10 \cdot 3$ & $7 \cdot 4$ & $13 \cdot 6$ \\
Not regularly (\%) & $37 \cdot 6$ & $46 \cdot 1$ & $29 \cdot 1$ & 34.3 \\
Unknown (\%) & $5 \cdot 5$ & $12 \cdot 6$ & $18 \cdot 7$ & $7 \cdot 9$ \\
\hline
\end{tabular}

implements had a significantly lower prevalence than experiment assistants ( $p<0.05$ ). No significant difference existed, however, in the proportion of each job category when the LAA group was compared in total with the non-LAA group. Table 6 shows job content in LAA and non-LAA subjects. More LAA subjects engaged in animal experiments, breeding, and quarantine duties than non-LAA subjects.

According to the frequency of handling animals, the exposed group was divided into two sub-groups: daily exposure group (five or more days per week) and non-daily exposure group. The prevalence of LAA in the daily exposure group (26.9\%) was significantly higher than in the non-daily exposure group (19.5\%)

Table 4 Frequency of own history and family history of allergy in control and exposed groups

\begin{tabular}{|c|c|c|c|}
\hline \multirow[b]{2}{*}{$\begin{array}{l}\text { History of } \\
\text { allergy }\end{array}$} & \multirow{2}{*}{$\begin{array}{l}\text { Control } \\
\text { group }(\%) \\
(n=251)\end{array}$} & \multicolumn{2}{|l|}{ Exposed groups } \\
\hline & & $\begin{array}{l}\text { Non-LAA subjects } \\
(n=4337)\end{array}$ & $\begin{array}{l}\text { LAA subjects } \\
(n=1304)\end{array}$ \\
\hline $\begin{array}{l}\text { Own history } \\
\text { Family history }\end{array}$ & $\begin{array}{l}30 \cdot 7 \\
28 \cdot 7\end{array}$ & $\begin{array}{l}30 \cdot 4 \\
22 \cdot 9\end{array}$ & $\begin{array}{l}59 \cdot 2^{\star \star}+ \\
39 \cdot 5^{\star \star}+\end{array}$ \\
\hline
\end{tabular}

$\star \star$ Significantly different from the control group (p $<0.01)$. + Significantly different from the non-LAA group ( $p<0.01)$. 
Table 5 Job categories in $L A A$ and non- $L A A$ subjects

\begin{tabular}{|c|c|c|c|c|}
\hline Job categories & No of subjectst & $\begin{array}{l}L A A \text { subjects }(\%) \\
(n=1304)\end{array}$ & $\begin{array}{l}\text { Non-LAA subjects }(\%) \\
(n=4302)\end{array}$ & $\begin{array}{l}\text { Prevalence } \\
\text { of } L A A(\%)\end{array}$ \\
\hline Researchers & 3236 & $57 \cdot 9$ & $57 \cdot 2$ & $23 \cdot 3$ \\
\hline Experimental assistants & 1100 & $21 \cdot 2$ & $19 \cdot 0$ & $25 \cdot 1^{\star}$ \\
\hline Animal husbandry & 1130 & $20 \cdot 8$ & $19 \cdot 8$ & $24 \cdot 0$ \\
\hline Personnel carrying out cleaning and washing & 380 & $5 \cdot 6$ & $7 \cdot 1$ & $19 \cdot 2$ \\
\hline
\end{tabular}

* Significantly different from cleaning and washing personnel $(\mathrm{p}<0.05)$.

† Some subjects had two or more job categories.

(table 7). Also, the frequency of history in the daily exposure group $(56.5 \%)$ was significantly lower than in the non-daily exposure group $(62.9 \% ; \mathrm{p}<0.05)$. Similar differences were also found for family history.

The prevalence of LAA rose as the number of handled species increased from one to five (table 8).

To estimate the correlation between symptoms and animal species, we examined the differences in the proportion of LAA subjects citing each species as a percentage of LAA subjects who actually handled the species (fig 4). Rabbits were cited by $60.5 \%$ of the LAA subjects with nasal symptoms who handled them and by $51.9 \%$ of those with respiratory symptoms who handled them. Figure 4 shows equivalen 1 data for other animal species.

Figure 5 shows the distribution of latency of symptoms by different animal species (data on eye symptoms not shown). Information on the latent period was obtained from LAA subjects who knew the animal species relevant to their symptoms. No significant difference was found in the mean latent periods between individual species for any symptoms. The proportion of LAA subjects who developed symptoms during the year of first exposure to the species was the highest in those citing rabbits for all symptoms.

\section{Discussion}

The present study was the first large scale survey of the prevalence of LAA in Japan. Prevalence was $23.1 \%$ and corresponds to the range reported in the United Kingdom and the United States. ${ }^{1-812} 13$ This

Table 6 Job content in LAA and non-LAA subjects

\begin{tabular}{lll}
\hline Job content ${ }^{\dagger}$ & $\begin{array}{l}\text { LAA subjects } \\
(n=1304)\end{array}$ & $\begin{array}{l}\text { Non-LAA subjects } \\
(n=4337)\end{array}$ \\
\hline Animal experimentation & $82 \cdot 4^{\star \star}$ & $74 \cdot 3$ \\
Breeding & $48 \cdot 0^{\star \star}$ & $43 \cdot 9$ \\
Quarantining & $9 \cdot 4^{\star}$ & $7 \cdot 4$ \\
Washing and sterilising & $17 \cdot 3$ & $16 \cdot 3$ \\
Cleaning rooms & $10 \cdot 5$ & $9 \cdot 9$ \\
Others & 11.3 & 12.6 \\
\hline
\end{tabular}

* Significantly different from non-LAA group $(\mathrm{p}<0.05)$.

$\star \star$ Significantly different from non-LAA group $(p<0.01)$.

+ Some subjects selected two or more job contents.

$\ddagger$ Rooms except animal rooms. prevalence, however, may be underestimated. People who had developed LAA had significantly shorter duration of exposure than the non-LAA group (fig 2). This is evidence that some animal handlers who had become aware of their LAA symptoms had removed themselves from exposure. Of those who did not participate in our survey some apparently did not submit a questionnaire because of concern about admitting to having LAA symptoms.

Of course, questionnaires have a number of limitations and in this case the questionnaire was administered to the subjects without medical interview or immunological investigations. Therefore, primarily irritant symptoms may be, in part, included in LAA symptoms in this survey.

On this point, after the present survey, Hanada (one of the members of our project group on the LAA study) ${ }^{14}$ showed findings that partly supported the reliability of our questionnaire survey. He carried out skin tests to guinea pig extracts in 38 subjects who had been listed as guinea pig handlers according to the questionnaire survey and included five LAA subjects citing guinea pig. All five LAA subjects reacted to urine, saliva, and epithelium and four reacted to serum. Twelve per cent of 33 subjects without LAA symptoms reacted to urine. These findings suggest that the specificity of our questionnaire survey was good, at least for the guinea pig.

We found that the most common LAA symptom was rhinitis. Only $12.9 \%$ of the subjects with respiratory symptoms did not have rhinitis. These findings indicate that the development of respiratory symptoms is likely to follow that of nasal or eye symptoms and further suggests that allergens from animals sensitise mostly by way of the respiratory tract.

Concerning the latent period of LAA, most LAA subjects $(70 \%)$ developed symptoms during their

Table 7 Prevalence of $L A A$ by frequency of animals handling

\begin{tabular}{lll}
\hline Frequency of exposure & No of subjects & Prevalence of LAA \\
\hline Non-daily & 2852 & $19 \cdot 5$ \\
Daily & 2789 & $26 \cdot 9 \star \star$ \\
\hline
\end{tabular}

$\star \star$ Significant at $\mathrm{p}<0.01$. 
Table 8 Number of animal species handled in LAA and non- $L A A$ subjects

\begin{tabular}{llll}
\hline $\begin{array}{l}\text { No of } \\
\text { animal species } \\
\text { handled }\end{array}$ & $\begin{array}{l}\text { LAA } \\
\text { subjects }(\%) \\
(n=1304)\end{array}$ & $\begin{array}{l}\text { Non-LAA } \\
\text { subjects } \% \%) \\
(n=4302)\end{array}$ & $\begin{array}{l}\text { Prevalence } \\
\text { of } L A A(\%)\end{array}$ \\
\hline $1^{\star \star}$ & $25 \cdot 9$ & $37 \cdot 3$ & $17 \cdot 8$ \\
2 & $24 \cdot 1$ & $25 \cdot 9$ & $22 \cdot 5$ \\
$3^{\star \star}$ & $17 \cdot 6$ & $13 \cdot 3$ & $29 \cdot 3$ \\
$4^{\star \star}$ & $12 \cdot 6$ & $9 \cdot 7$ & $29 \cdot 0$ \\
$5^{\star \star}$ & $9 \cdot 1$ & $5 \cdot 3$ & $35 \cdot 2$ \\
6 & $5 \cdot 6$ & $3 \cdot 9$ & $31 \cdot 2$ \\
7 & $2 \cdot 5$ & $2 \cdot 7$ & $22 \cdot 7$ \\
8 & $2 \cdot 6$ & $2 \cdot 0$ & $29 \cdot 0$ \\
\hline
\end{tabular}

* Significantly different between both groups by numbers of species handled $(\mathrm{p}<0.01)$.

first three years of exposure; this confirms the findings reported by other investigators, ${ }^{56}$ and suggests that persons who do not become allergic to laboratory animals during three years are unlikely to develop LAA after this. Possibly it also supports the suggestion that short periods of high exposure are more important than the equivalent dose accumulated by lower exposure over a longer time. ${ }^{15}$

Preventing the ingress of animal allergens would be a primary preventive measure. In the present survey, the number of LAA subjects who reported the availability of protective equipment for LAA symptoms was less than half of those with nasal or respiratory symptoms. These findings suggest that personal protective equipment is unlikely ever to prevent completely the manifestation of LAA. Other methods to decrease allergens in the air are required. Recently, our co-workers have developed a one way airflow type ventilation system. ${ }^{16}$ This system draws air contaminated with allergens from the work area to the back of the racks and cages and thus away from human contact. They showed that this system could suppress the diffusion of airborne allergens toward

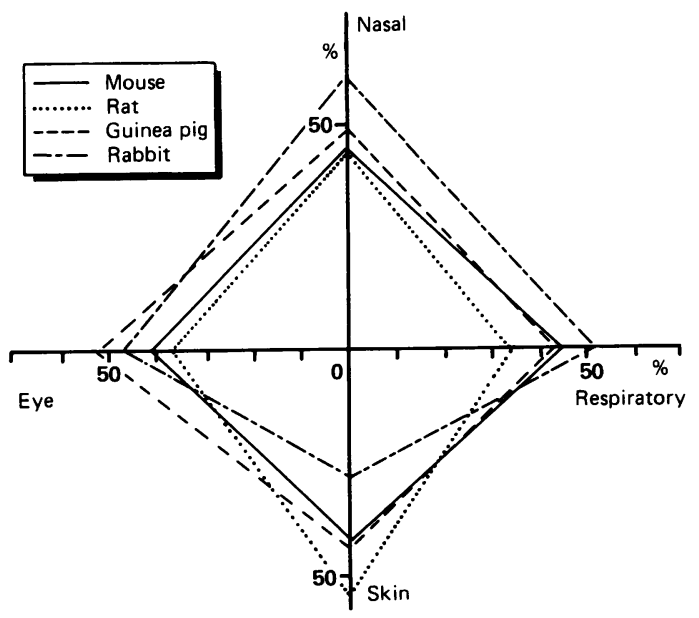

Figure 4 Relations between LAA symptoms and causal species. the work area of animal rooms and reduced symptoms in those with LAA.

The relation between the development of LAA and atopy has been studied by several researchers. Asthma resulting from LAA has been reported to associate with atopy as defined by skin tests with common antigens. ${ }^{481718}$ In the present study, a significant correlation between the development of LAA and atopy, defined by personal history or family history of allergy, was found. The finding that atopic persons are more likely to have LAA symptoms than non-atopic persons supports the findings of some other authors. ${ }^{511-13}$

In studying the relation between the development of LAA and the density of exposure, several researchers ${ }^{25} 11$ have failed to find a correlation and have suggested the operation of self selection bias as the reason for the failure. In their work, the density of exposure has been based on job category. In the present study, the prevalence of LAA in the staff responsible for cleaning and washing was significantly lower than that in experimental assistants. Most of them appeared to be indirectly or more lightly exposed to animals. No significant association between job categories and the development of LAA was found, however. It seems that job categories are not well enough categorised in Japan to find any effect, especially in medical schools. We tried to use the actual content of work as an index of the density of exposure and found a significant correlation between the development of LAA and some jobs. Animal experimentation, breeding, and quarantining, we assumed to have relatively heavy exposure. Even so no differences could be found for the prevalence of LAA between these job categories.

Taking the frequency of handling (days a week) as another index of the density of exposure, we found a significant correlation between the development of LAA and the density of exposure. The finding that the prevalence of LAA in daily exposed subjects was significantly higher than in the non-daily exposed we suggest is strong evidence of a dose-effect relation. On the other hand, for LAA subjects, the frequency of atopy in the non-daily exposure group was significantly higher than in the daily exposure group. This finding is probably evidence of self selection. A significant relation between the development of LAA and the number of animal species handled was also found. Handling a larger number of species may result in an increase in "dose" and may also increase the chance to meet animal species to which the handler is likely to become allergic.

Previous studies of $\mathrm{LAA}^{2419}$ have shown that rats and mice were the main causal species. In the present study, most subjects handled two or more species and mice and rats are widely used in facilities in Japan, but the prevalence of LAA indicated that guinea pigs and rabbits were also important causal species. 
46

Aoyama, Ueda, Manda, Matsushita, Ueda, Yamau
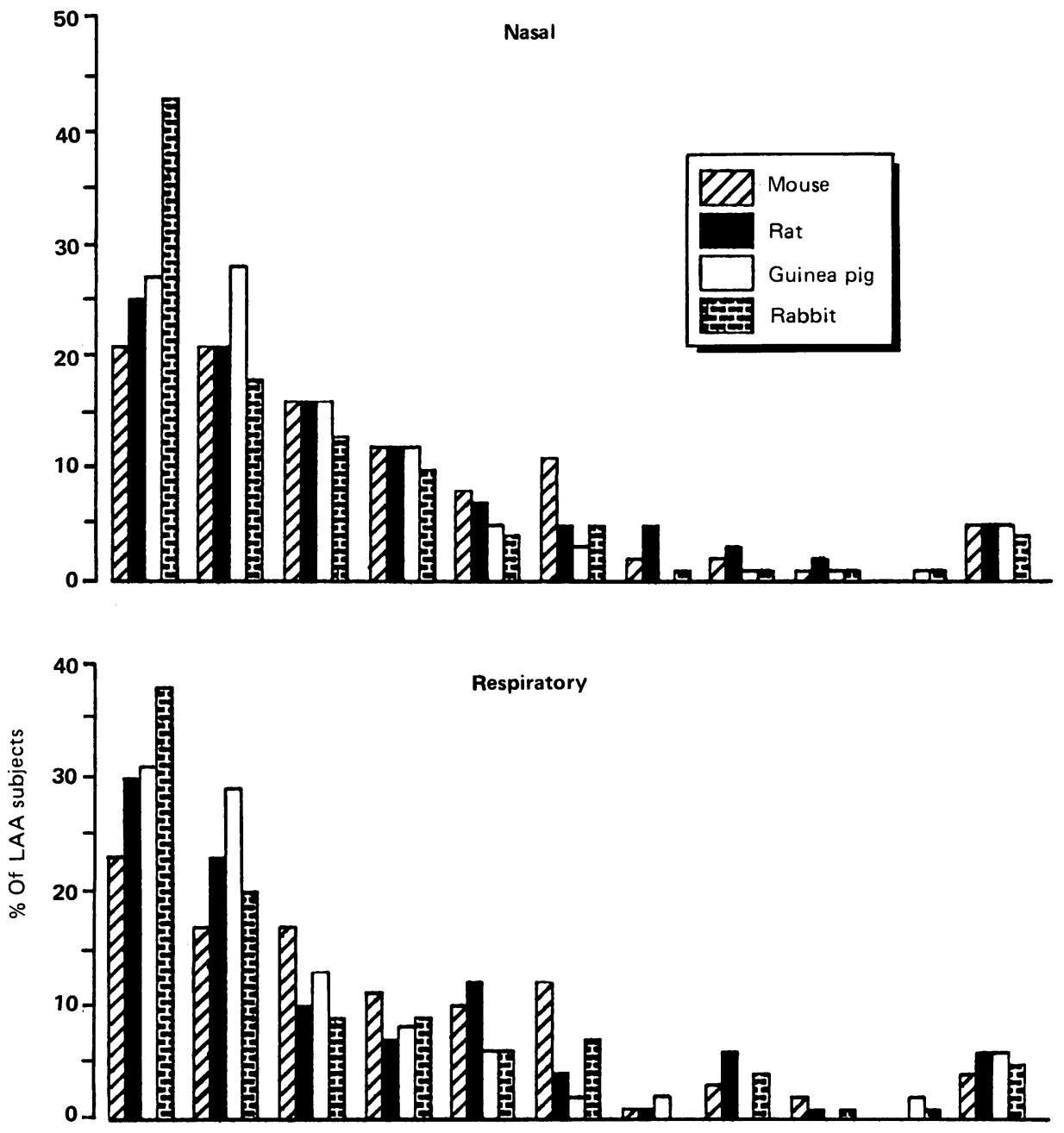

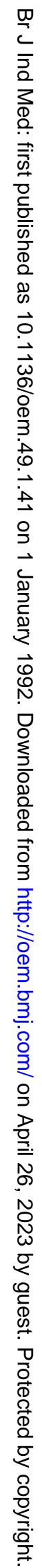

Figure 5 Distribution of latency by different species. 
We considered that it would be profitable for the prevention of LAA to know the detailed symptoms caused by different species and the allergenicity of those species. Comparing the proportion of LAA subjects citing each species as a percentage of those who actually handled the species we estimated the relation between symptoms and species. We consider that characteristic relations between symptoms and species can be seen (fig 5). Associations between exposure to rabbits and nasal symptoms and between exposure to rats and skin symptoms have been shown in previous reports. ${ }^{2021}$ Their relations may reflect the nature of antigens and exposure forms in different species.

The proportion of LAA subjects who developed symptoms during the year of the first exposure to a species was highest in those citing rabbits for all symptoms. These findings may imply a higher concentration of airborne allergens ${ }^{22}$ or the high allerger.icity of allergens derived from rabbits, although primary irritancy cannot be excluded.

We are grateful for the cooperation of many laboratory animal facilities in Japan. The publication of this work was supported by the Kodama Foundation for Medical Research. The work was financed by a grant in aid for Scientific research 60480486 (19857) from the Japanese Ministry of Education, Science, and Culture.

Requests for reprints to: Kohji Aoyama, Department of Environmental Medicine, Faculty of Medicine, Kagoshima University, Sakuragaoka, Kagoshima 890 , Japan.

1 Lincoln TA, Bolton NE, Garrett AS. Occupational allergy to dander and sera. J Occup Med 1974;16:465-9.

2 Lutsiky I, Neuman I. Laboratory animal dander allergy: I. An occupational disease. Ann Allergy 1975;35:201-5.

3 Newman Taylor AJ, Longbottom JL, Pepys J. Respiratory allergy to urine proteins of rats and mice. Lancet 1977;ii:847-9.
4 Lutsky I, Toshner D. A review of allergic respiratory disease in laboratory animal workers. Lab Anim Sci 1978;28:751-6.

5 Gross NJ. Allergy to laboratory animals: Epidemiologic, clinical, and physiologic aspects, and a trial of cromolyn in its management. J Allergy Clin Immunol 1980;66:158-65.

6 Cockcroft A, Edwards J, McCarthy P, Andersson N. Allergy in laboratory animal workers. Lancet $1981 ; \mathrm{ii}: 827-30$.

7 Slovak AJM, Hill RN. Laboratory animal allergy: a clinical survey of an exposed population. $\mathrm{Br} J$ Ind $\mathrm{Med} 1981 ; 38: 38-41$.

8 Davies GE, Mcardle LA. Allergy to laboratory animals: A survey by questionnaire. Int Arch Allergy Appl Immunol $1981 ; 64: 302-7$.

9 Slovak AJM. Achieved objectives in laboratory animal allergy research: Their significance for policy and practice. New Engl Reg Allergy Proc 1987;8:189-94.

10 Newman Taylor AJ. Laboratory animal allergy. Eur J Respir Dis 1982;123(suppl):60-4

11 Bland SM, Levine MS, Wilson PD, Fox NL, Rivera JC. Occupational allergy to laboratory animals: An epidemiologic study. J Occup Med 1986;28:1151-7.

12 Venables KM, Tee RD, Hawkins ER, Gordon DJ, Wale CJ, Farrer NM, et al. Laboratory animal allergy in a pharmaceutical company. Br J Ind Med 1988;45:660-6.

13 Kibby T, Powell G, Cromer J. Allergy to laboratory animals: A prospective and cross-sectional study. J Occup Med 1989; 31:842-6.

14 Hanada $T$. Clinical and immunologic study of patients allergic to laboratory animals (LAA): With special attention to upper airway allergy to guinea pig. Practica Otologica (Kyoto) 1989;82:1453-64. (In Japanese.)

15 Venables KM. Epidemiology and the prevention of occupational asthma. $\mathrm{Br} J$ Ind $\mathrm{Med}$ 1987;44:73-5.

16 Yamauchi C, Obara T, Fukuyama N, Ueda T. Evaluation of a one-way airflow system in an animal room based on counts of airborne dust particles and bacteria and measurements of ammonia levels. Lab Anim 1989;23:7-15.

17 Beeson MF, Dewdney RG, Edwards DL, Orr RG. Prevalence and diagnosis of laboratory animal allergy. Clin Allergy 1983;13:433-42.

18 Slovak AJM, Hill RN. Does atopy have any predictive value for laboratory animal allergy? A comparison of different concepts of atopy. Br J Ind Med 1987;44:129-32.

19 Lutsky I, Kalbfleisch JH, Fink JN. Occupational allergy to laboratory animals: employer practices. J Occup Med 1983; 25:372-6.

20 Agrup G, Sjostedt L. Contact urticaria in laboratory technicians working with animals. Acta Derm Vernereol (Stockh) 1985; 65:111-5.

21 Botham PA, Davies GE, Teasdale EL. Allergy to laboratory animals: a prospective study of its incidence and of the influence of atopy on its development. $\mathrm{Br} J$ Ind Med 1987; 44:627-32.

22 Edwards RG, Beeson MF, Dewdney JM. Laboratory animal allergy: the measurement of airborne urinary allergens and the effects of different environmental conditions. Lab Anim 1983;17:235-9.

Accepted 20 May 1991 